http://jmscr.igmpublication.org/home/

ISSN (e)-2347-176x ISSN (p) 2455-0450

crossref DOI: https://dx.doi.org/10.18535/jmscr/v7i11.158

Journal Of Medical Science And Clinical Research

\title{
Prevalence of Medical Disorders in Pregnancy and Pregnancy Outcome at a Tertiary Level Hospital: A Retrospective Analysis
}

\author{
Authors \\ Rajasingh Revathi ${ }^{1}$, Davidbaskaran Sherin Raja Janaki ${ }^{2} *$ \\ ${ }^{1}$ Assistant Professor, Department of Obstetrics and Gynecology, Tagore Medical College and Hospital \\ Chennai, INDIA \\ ${ }^{2}$ Assistant Professor, Department of General Medicine, Tagore Medical College and hospital Chennai, \\ INDIA \\ *Corresponding Author
}

\section{Dr Sherin Raja Janaki Davidbaskaran}

Assistant Professor, Department of General Medicine, Tagore Medical College And Hospital.

Rathinamangalam, Chennai-600127, India

\begin{abstract}
Background: When Pregnancy is associated with an underlying medical disorder, it has a large impact on the well-being of a mother. So to determine the prevalence and pattern of various medical disorders in pregnancy is very important.

Aim: This study seeks to retrospectively determine the incidence of medical disorders in pregnancy, and also determine their impact on fetal and maternal outcome.

Materials and Methods: This was a retrospective study of all medical cases in pregnancy managed in TAGORE MEDICAL COLLEGE AND HOSPITAL from 1st of January 2017 to 31st October 2019. Data were analyzed and results were presented in simple tables. Test statistics was set at $95 \%$ confidence interval.

Results: A total of 198 medical cases in pregnancy of 2418 admissions were managed during the study period (8.2\%). Mean (SD) age of the women was 30 years and age ranged $18-42$ years for about 198 cases that had the age documented. Most common medical disorder was pregnancy induced hypertension and its complication seen in $38.85 \%$ of the females, followed urinary tract infection seen in $19.19 \%$ patients. Caesarean section rate in women with medical condition in pregnancy was higher than in the control group (69.6\% vs. 34.2\%). Maximum perinatal morbidity was seen in females suffering with hypertensive disorders $(53.4 \%)$, with $12(54.5 \%)$ IUGR and 2(40\%) intra uterine demise respectively.

Conclusion: There is relatively little change in the incidences of medical complication over the period of time. Preventive strategies may have reduced the prevalence over the years. However, more effort is needed to markedly reduce the medical complications in pregnancy.

Keywords: Medical disorders, Pregnancy, Prevalence, Hypertension, Fetal outcome, Maternal outcome.
\end{abstract}

\section{Introduction}

The prevalence of medical problems in pregnancy is increasing because of a complex interplay between demographic and lifestyle factors.
Women are delaying child bearing until later in life. Older women are more likely to have acquired medical disorders, such as hypertension and obesity; they are also at higher risk of 
gestational diabetes and venous thromboembolism $^{[1]}$ Approximately $20 \%$ of maternal deaths are the result of preexisting conditions that are exacerbated by pregnancy or its management. ${ }^{[2]}$

It is, however, important to note that a number of unbooked women will present in labor with a number of complications of which medical disorder is one. Second, the awareness of some of these medical disorders by pregnant women is low in some cases. ${ }^{[3]}$ The implication of this is that in situations where routine screening is not being practiced, some of these medical disorders may be missed or diagnosed late at the time of delivery. This does not give room for optimal care and may affect maternal and/or fetal health adversely. Earlier studies have also found that 87 to $94 \%$ of women will report at least one health problem in the immediate puerperium. ${ }^{[4]}$

Over past years maternal mortality has decreased worldwide. In comparison to the developed nations, it is still higher in developing countries. ${ }^{[5]}$ Previously, any medical disorders during pregnancy had a much worse outcome in terms of both maternal and fetal health. With the advancement in all the sectors especially in maternal/fetal medicine, obstetric anesthesia and pediatrics, more fruitful outcome can be anticipated even in pregnancies with the medical disorders.

Medical conditions in pregnancy one of the leading causes of maternal death. Therefore, it is vital that all physicians acquire a basic knowledge and understanding of medical problems in pregnancy. The process should begin before conception, and all physicians should consider delivering prepregnancy counselling as part of their routine inpatient or outpatient consultations with women of reproductive age.

\section{Materials and Methods}

This retrospective study was conducted at the Department of Obstetrics and Gynaecology and Department of General Medicine of tertiary care hospital by reviewing all medical records of pregnant patients with medical disorders admitted for delivery from 1st of January 2017 to 31st October 2019.

All data was retrieved and entered in preformed, structured, validated proforma regarding information of sociodemographic factors, gravid, parity, gestational age at presentation high risk factors, and the antenatal, intranatal and postnatal events during this pregnancy, neonatal outcome. On presentation, the women are clerked and relevant information obtained which includes; indication for booking, medical history, and past obstetric history. They are examined and afterward, investigated and screened for any medical condition by the use of urinalysis, fasting blood sugar if indicated, and genotype. Patients found to have medical conditions are co-managed with the relevant physician. Data collected was analysed using simple statistical measures like percentage and proportion.

\section{Inclusion Criteria}

- All females booked with our institute and diagnosed to have medical disorder preconceptionally or antenatally.

\section{Exclusion Criteria}

- Unbooked patients with medical complications.

- Pre-existing medical conditions leading to abortion in first trimester.

- Pregnant women with surgical disorders.

\section{Results}

During the study period out of 2418 pregnant women admitted, 198(8.18\%) had medical disorders. The age ranged from 18 to 42 years with the mean age of 30 years. In the present study majority of the mothers were in the age group of $20-35$ years $(74 \%)$, while remaining $24 \%$ were in the age group of $>35$ years. (Table 1 ).

Table 1: Demographic Details.

\begin{tabular}{|l|c|c|}
\hline Age in Years & No of patients & Percentage \% \\
\hline$<20$ & 4 & 2 \\
\hline $20-35$ & 146 & 74 \\
\hline $35-42$ & 48 & 24 \\
\hline
\end{tabular}


In this study, 136 females were primigravida, 48 were multigravida and 14 females were grand multigravida. (Table-2). Among 198 prgnances $62.6 \%$ females delivered after completing the term and $33.8 \%$ delivered pre-term out of which $2.5 \%$ delivered before completing 28 weeks of gestation. Among the five pregnancies which were terminated before 28 weeks of gestation 4 had preeclampsia and 1 had uncontrolled gestational diabetes mellitus. (Table -3)

Table -2 Number of Pregnancy

\begin{tabular}{|l|c|c|}
\hline Gravida & No of patients & Percentage \% \\
\hline Primigravida & 136 & 68.6 \\
\hline Multigravida & 48 & 24.2 \\
\hline Grandmulti & 14 & 7.1 \\
\hline
\end{tabular}

Table -3 Period of Gestation (in Weeks)

\begin{tabular}{|c|c|c|}
\hline Gestation in weeks & No of patients & Percentage\% \\
\hline$<28$ & 5 & 2.5 \\
\hline $28-36$ & 67 & 33.8 \\
\hline $37-40$ & 124 & 62.6 \\
\hline$>40$ & 2 & 1.1 \\
\hline
\end{tabular}

Table 4: Medical Disorders in Pregnancy

\begin{tabular}{|c|c|c|}
\hline \multicolumn{2}{|l|}{ Medical Dosorders } & Number of \\
\hline \multirow{4}{*}{$\begin{array}{l}\text { Hypertensive } \\
\text { Disorders } \\
\text { (71pts, 38.85\%) }\end{array}$} & Gestational Hypertension & 35 \\
\hline & Pre-eclampsia & 18 \\
\hline & Chronic Hypertension & 12 \\
\hline & Eclampsia & 6 \\
\hline \multirow{3}{*}{$\begin{array}{l}\text { Urinary Tract } \\
(38 \text { pts, } 19.19 \%)\end{array}$} & Urinary tract infection & 28 \\
\hline & Pyelonephritis & 6 \\
\hline & Chronic kidney disease & 4 \\
\hline \multirow{2}{*}{$\begin{array}{l}\text { Hematological } \\
\text { disorder } \\
\text { (35pts, } 17.67 \% \text { ) }\end{array}$} & Severe anemia & 34 \\
\hline & Sickle cell disease & 1 \\
\hline \multirow{2}{*}{$\begin{array}{l}\text { Endocrine } \\
(26 p t s, 13.13 \%)\end{array}$} & Thyroid disorders & 22 \\
\hline & $\begin{array}{c}\text { Gestational diabetes } \\
\text { mellitus }\end{array}$ & 4 \\
\hline \multirow{3}{*}{$\begin{array}{l}\text { Respiratory } \\
(12 \mathrm{pts}, 6.06 \%)\end{array}$} & Asthma & 8 \\
\hline & Tuberculosis & 2 \\
\hline & Lobar pneumonia & 2 \\
\hline \multirow{2}{*}{$\begin{array}{l}\text { Cardiac disease } \\
(2 \mathrm{pts}, 1 \%)\end{array}$} & RHD & 1 \\
\hline & Arrythmias & 1 \\
\hline \multirow{3}{*}{$\begin{array}{l}\text { Gastrointestinal } \\
\text { disease } \\
(8 \text { pts }, 4.2 \%)\end{array}$} & AGE & 2 \\
\hline & APD & 5 \\
\hline & Hepatitis & 1 \\
\hline \multirow{2}{*}{$\begin{array}{l}\text { Neurological disorder } \\
(2 \mathrm{pts}, 1 \%)\end{array}$} & Seizure disorder & 1 \\
\hline & Cerebral malaria & 1 \\
\hline $\begin{array}{l}\text { Dermatological disease } \\
(1 \mathrm{pts}, 0.5 \%)\end{array}$ & Pururitis gravidarum & 1 \\
\hline \multirow{2}{*}{$\begin{array}{l}\text { Systemic infection } \\
(2 \mathrm{pts}, 1 \%)\end{array}$} & Chicken pox & 1 \\
\hline & HIV & 1 \\
\hline $\begin{array}{l}\text { Autoimmune } \\
(1 \mathrm{pts}, 0.5 \%)\end{array}$ & $\begin{array}{l}\text { Systemic lupus } \\
\text { erythematosus }\end{array}$ & 1 \\
\hline
\end{tabular}

Most common medical disorder was pregnancy induced hypertension and its complication like pre-ecclampsia, eclampsia, seen in $38.85 \%$ of the females; followed by urinary tract infection seen in $19.19 \%$ patients. (Table-4)

Out of the 43 females suffering from PIH, 6 females had eclampsia and 18 females had preecclampsia for which they were managed medically and 4was managed by terminating the pregnancy. Urinary tract infections (28) and pyelonephritis (6) accounted for about $19.19 \%$ of all the medical disorders during the study period (table-4). 12 out of 34 anaemic females required blood transfusion before delivery, others treated by medically.

Out of Twenty-two women 21 had hypothyroidism while Graves's disease was seen in one woman during the study period. Respiratory disorders were seen among 12 women among whom asthma (8) was the commonest one followed by tuberculosis. Among the four cases of diabetes with pregnancy two-third of them had gestational diabetes mellitus while rest had overt diabetes (table - 4). Acute gastro-enteritis necessitating admission was found among one pregnant women. Cardiac disease was seen in 2 women at admission and one woman had psychiatric disorder during the study period.. One women each had chicken pox and HIV positive status at the time of admission.

Caesarean section rate in women with medical condition in pregnancy was higher than in the control group (69.6\% vs. $34.2 \%$ ). Surprisingly, the rate of instrumental delivery was lower than in the control group (1.5\%vs. 2.1\%). Table 3 gives detail summary of the mode of delivery in both groups. For those who had vaginal delivery, labor was found to be significantly shorter in women with medical conditions in pregnancy compared to healthy parturients. (Table-5)

Table -5 Mode of Delivery

\begin{tabular}{|l|c|c|}
\hline \multirow{2}{*}{ Mode of Delivery } & \multicolumn{2}{|c|}{ Medical disorder } \\
\cline { 2 - 3 } & $\mathrm{NO}(2220) 91.8 \%$ & $\begin{array}{c}\text { YES(198) } \\
8.2 \%\end{array}$ \\
\hline $\begin{array}{l}\text { Spontaneous vaginal } \\
\text { delivery }\end{array}$ & 1386 & 45 \\
\hline Assisted breech delivery & 26 & 2 \\
\hline Forceps delivery & 16 & 1 \\
\hline Vacuum delivery & 32 & 2 \\
\hline Elective caesarean section & 224 & 102 \\
\hline $\begin{array}{l}\text { Emergency caesarean } \\
\text { section }\end{array}$ & 536 & 36 \\
\hline
\end{tabular}


On analysis of outcome of pregnancy in relation to various medical disorders it was see that maximum perinatal morbidity was seen in females suffering with hypertensive disorders (53.4\%), with $12(54.5 \%)$ IUGR and 2(40\%) intra uterine demise respectively. Following $\mathrm{PIH}$, higher rate of perinatal morbidity was seen in anaemic $6(27 \%$ IUGR) and hypothyroid2 (9\% IUGR) females.Table-6

Table-6 Outcome of Pregnancy

\begin{tabular}{|l|c|c|}
\hline Outcome of pregnancy & No. of patients & Percentage \\
\hline Normal for gestation & 164 & $82.8 \%$ \\
\hline IUGR & 22 & $11.1 \%$ \\
\hline Macrosomia & 2 & $1 \%$ \\
\hline IUFD/Still birth & 5 & $2.5 \%$ \\
\hline Abortion & 5 & $2.5 \%$ \\
\hline
\end{tabular}

\section{Discussion}

The prevalence of medical disorder was $20 \%$ $27 \%$ reported in various studies where a wide range of medical disorder were also assessed ${ }^{[6]}$, in our study it was $8.2 \%$. Medical disorder in pregnancy presents a significant risk to foetal well-being, such as premature birth, small for date infant or still births and early neonatal death. Identification of patients at risk for these complicated pregnancies with poor outcome is fundamental to antenatal care. If a female may suffer from more than one medical disorders resulting in high risk pregnancy and poor outcome of it.

Hypertension was found to be the most common medical condition in the women studied with its various manifestations. This is not surprising as hypertension has been found to be one of the commonest medical disorders in pregnancy ${ }^{[7]}$ Preeclampsia often occurs de novo, but women with pre-existing hypertension may develop superimposed preeclampsia, and gestational hypertension may also evolve into pre-eclampsia. It requires hospital admission for close monitoring and the only cure is delivery, which may be required urgently in severe cases.

Recent evidence from the CHIPS trial 30 showed that neonatal outcomes are no different with a target diastolic blood pressure of $81-85 \mathrm{mmHg}$ compared with 100-104 $\mathrm{mmHg}$ and severe maternal hypertension was more frequent in the less tight control (100-104 $\mathrm{mmHg}$ ) group. Therefore, when treating hypertension in pregnancy, the aim should now be tight control, with a target diastolic blood pressure of $81-85$ $\mathrm{mmHg}^{\cdot[8]}$

Urinary tract infection is the second most common medical disorder in this study which is comparable to the Nigerian study. ${ }^{[9]}$ There is abound evidence that UTI causes adverse maternal and fetal outcomes. ${ }^{[10]}$ The rates of intrauterine growth retardation (IUGR), pre-term delivery, cesarean section and pre-eclampsia have all been shown to be higher in patients treated for UTIs. The consequences of untreated infections are even worse and could lead to pyelonephritis, chronic renal insufficiency, IUGR, pre-term delivery and still birth with considerable morbidity and mortality ${ }^{[11]}$ This underlines the significance of appropriate diagnosis and treatment of these infections, especially in pregnant women.

Severe anemia is not only concentrated among women at pregnancy but also before pregnancy that continues to be a major public health problem. It has been estimated that more than onethird of the world's women are anemic; the vast majority of this being in developing countries. ${ }^{[12]}$ Cardiac disease during pregnancy in this study is $(0.08 \%)$ much less compared to a study done $(0.8 \%)$ in India, where 59 cardiac cases out of 7053 deliveries was found. ${ }^{[13]}$

Researchers have attributed changes in the incidence of medical disorders to changing maternal age due to women delaying childbearing as a consequence of marrying at a later age and the pursuit of professional goals. ${ }^{[14]}$ Because of the improvements in the medical, obstetric, and anesthetic management of pregnancy, many women with medical disorders can go through a pregnancy without major problems and the contribution of medical disorders to maternal mortality is reducing remarkably.

The management of medical complications requires carefulness as the physiological changes in pregnancy mimic the signs and symptoms of 
certain medical conditions, especially cardiovascular and the respiratory systems as well as certain endocrine disorders, for example, the first signs and symptoms of disordered thyroid function maybe mimicked by pregnancy itself ${ }^{[15]}$

\section{Conclusion}

By determining the prevalence and pattern of medical disorders in pregnancy at the time of delivery, we will be able to formulate or modify health policies to facilitate early recognition of these problems and institute treatment promptly prior to delivery or prepare for complications that may arise in the puerperium. It will also give room towards distribution of resources such as adequate provision of appropriate medications and diagnostic equipment and serve as a basis for the development of protocols to improve standard of care in all health facilities that care for pregnant women. It will also enhance identification of areas where manpower training should be directed.

\section{References}

1. Knight $M$, Tuffnell D, Kenyon $S$ et al. S aving lives, improving mothers' care: surveillance of maternal deaths in the UK 2011-13 and lessons learned to inform maternity care from the UK and Ireland Confidential Enquiries into Maternal Deaths and Morbidity 2009-13 . Oxford : University of Oxford, 2015 .

2. Reduction of Maternal Mortality: A joint WHO/UNFPA/UNICEF/World bank statement. Geneva: World Health Organization; 1999. p.14. Available from: http://whqlibdoc.who.int/publications/199 9/9241561955_eng.

3. Ngaira JAM, Kimotho J, Mirigi I, Osman S, Ng'ang'a Z, Lwembe R, etal. Prevalence, awareness and risk factors associated with hepatitis B infection among pregnant women attending the antenatal clinic at Mbagathi District Hospital in Nairobi, Kenya. Pan Afr Med J 2016;24:315.
4. Glazener CMA, Abdalla M, Stroud P, Naji S, Templeton A, Russell IT. Postnatal maternal mortality: Extent, causes, prevention and treatment. $\mathrm{Br} \mathrm{J}$ Obstet Gynaecol 1995;102:282-7

5. Trends in maternal mortality: 1990 to 2013. Estimates by WHO, UNICEF, UNFPA. The World Bank and the United Nations Population Division;2014. ISBN 978924150722.

6. Kersten I, Lange AE, Haas JP. Chronic disease in pregnant women: Prevalence and birth outcomes based on the SNiP study. BMC Pregnancy Childbirth 2014;14:75.

7. Yücesoy G, Ozkan S, Bodur H, Tan T, Calişkan E, Vural B, et al. Maternal and perinatal outcome in pregnancies complicated with hypertensive disorder of pregnancy: A seven year experience of a tertiary care center. Arch Gynecol Obstet 2005;273:43-9.

8. Magee L, von Dadelzen P, Rey E et al. Less tight versus tight control of hypertension in pregnancy. N Engl J Med $2015 ; 372: 407-17$.

9. Dawkins JC, Fletcher HM, Rattray GA, Reid M, GordonStrachan G. Acute pyelonephritis in pregnancy: a retrospective descriptive hospital basedstudy. ISRN Obstet Gynecol.2012; 6 . doi:10.5402/2012/519321.

10. Management of urinary tract infections in adults. Scottish Intercollegiate Guidelines Network. Guideline No. 88. SIGN; 2006: 13-15.

11. Le J, Briggs GG, McKeon A, Bustillo G. Urinary tract infections during pregnancy. Ann Pharmacother 2004;38:1692-701.

12. Dangour AD, Hill HL, Ismail SJ. Haemoglobin status of adult non-pregnant Kazakh women living in Kzyl-Orda region, Kazakhstan. Eur J Clin Nutr. 2001; 55: 1068-1075. 
13. Shah TM, Mishra K, Ninama P, Parikh C . Diseases with pregnancy - a study of maternal and fetal outcome. IAIM. 2015;2(1);22-9.

14. Yong TT, Tay SK. Medical Disorders Ahead. Editorial. Ann Acad Med 2002;31:33.

15. Bishnoi A, Sachmechi I. Thyroid disease during pregnancy. Am Fam Physician 1996;53: 215-20. 